\title{
Effects of Thylakoid-Rich Spinach Extract on the Pharmacokinetics of Drugs in Rats
}

\author{
Yuji Saito, Tomoaki Usami, Miki Katoh, and Masayuki Nadai* \\ Department of Pharmaceutics, Faculty of Pharmacy, Meijo University; 150 Yagotoyama, Tempaku-ku, Nagoya 468- \\ 8503, Japan.
}

Received August 17, 2018; accepted October 23, 2018

\begin{abstract}
Thylakoid-rich spinach extract is being used as dietary weight-loss supplements in Japan. A recent rat study has suggested that intake of thylakoid-rich spinach extract with dietary oil inhibits dietary fat absorption via binding to bile acids, which promotes excretion of bile acids in feces. While, we confirmed that a serving size of thylakoid-rich spinach extract contains a large amount of calcium $(130 \mathrm{mg} / 5 \mathrm{~g})$. Therefore, using rats, we evaluated whether one-time ingestion of thylakoid-rich spinach extract affects the gastrointestinal absorption of water-insoluble drugs, such as griseofulvin (GF) and indomethacin (IM), or ciprofloxacin (CPFX) that chelate with polyvalent metal cations. Pretreatment of the rats with thylakoid-rich spinach extract $(100$ or $300 \mathrm{mg} / \mathrm{kg})$ for $15 \mathrm{~min}$ prior to oral administration of GF $(50 \mathrm{mg} / \mathrm{kg})$ or IM $(10 \mathrm{mg} / \mathrm{kg}) \mathrm{did} \mathrm{not}$ significantly alter the pharmacokinetic properties of either drug. Meanwhile, co-administration of thylakoidrich spinach extract $(500 \mathrm{mg} / \mathrm{kg})$ and CPFX $(20 \mathrm{mg} / \mathrm{kg})$ significantly reduced the peak plasma concentration and the area under the plasma concentration-time curve of CPFX to 25 and $40 \%$, respectively in rats. In vitro studies demonstrated that when a mixture of thylakoid-rich spinach extract and CPFX was centrifuged, there was a significant reduction in the supernatant concentration of CPFX relative to the control. When the experiment was repeated in the presence of ethylenediaminetetraacetic acid, the concentration of CPFX was unchanged. These results suggest that the intake of thylakoid-rich spinach extract may reduce the absorption of drugs that form a chelate with polyvalent metal cations, such as CPFX.
\end{abstract}

Key words dietary supplement-drug interaction; thylakoid-rich spinach extract; bile acid; metal cation; chelation

\section{INTRODUCTION}

In recent years, the use of dietary supplements has increased dramatically, primarily owing to increased health awareness throughout the general population. This trend is not limited to healthy subjects, but also includes admitted and ambulatory patients in many countries. ${ }^{1-4)}$ Thus, the risk of dietary supplement-drug interactions is increasing, as dietary supplements are more likely to be taken with medications. In fact, studies have indicated that Hypericum perforatum, commonly known as St. John's wort, reduces the plasma concentrations of cyclosporine, digoxin and human immunodeficiency virus protease inhibitors, an effect that is mediated through the induced expression and activity of P-glycoprotein (ABCB1/P-gp) and CYP3A. ${ }^{5-7)}$ Moreover, multiple reports exist of adverse events and altered treatment effects for various medications that have been taken in conjunction with ginkgo biloba extract, cranberry juice extracts, turmeric and quercetin. ${ }^{8-11)}$ For this reason, risk assessments of dietary supplement-drug interactions are essential.

Thylakoid-rich spinach extract, a dietary supplement, is commonly obtained from baby spinach leaves using the $\mathrm{pH}$ method followed by drum drying, ${ }^{12)}$ and is being used for weight loss in Japan, as well as the U.S.A. and Europe. Clinical studies have demonstrated that thylakoid-rich spinach extract suppresses subjective hunger, promote body weight loss, and reduce low density lipoprotein cholesterol. ${ }^{13,14)}$ In rats, intake of thylakoid-rich spinach extract with dietary oil is suggested to inhibit dietary fat absorption via binding to bile acids, which promotes excretion of bile acids in feces. ${ }^{15)}$
It is also well documented that bile acids facilitate the gastrointestinal absorption of water-insoluble drugs by acting as a surfactant to enhance the drug's water solubility. ${ }^{16)}$ This suggests that thylakoid-rich spinach extract may reduce the gastrointestinal absorption of water-insoluble drugs by reducing the surfactant-like effect of bile acids in the dissolution process of water-insoluble drugs.

Alternatively, supplementation with thylakoid-rich spinach extract could interfere with medications through chelation. For instance, the nutrition facts of the thylakoid-rich spinach extract product, Appethyl $l^{\mathbb{B}}$, specifies that a serving size $(5 \mathrm{~g})$ of thylakoid-rich spinach extract contains $150 \mathrm{mg}$ calcium (Ca) and $6 \mathrm{mg}$ iron $(\mathrm{Fe})$. Co-administration of antacids, mineral supplements, and milk containing polyvalent metal cations, such as $\mathrm{Al}^{3+}, \mathrm{Mg}^{2+}, \mathrm{Ca}^{2+}$, and $\mathrm{Fe}^{2 / 3+}$, has been linked to decreased oral absorption of quinolone antibiotics - an interaction that has been attributed to the chelation between quinolones and polyvalent metal cations. ${ }^{17-22)}$ The resulting quinolone-polyvalent metal cation complexes exhibit decreased solubility and membrane permeability, ${ }^{23-25)}$ which leads to poor absorption in the gastrointestinal tract and ultimately decreased bioavailability. Furthermore, the absorption of tetracycline antibiotics is inhibited when the antibiotic is taken with antacids or Kampo preparations containing polyvalent metal cations through formation of a chelate. ${ }^{26,27)}$ As such, intake of thylakoid-rich spinach extract may reduce the plasma concentrations of quinolone and tetracycline antibiotics due to chelation. However, the pharmacokinetic interactions between thylakoid-rich spinach extract and water-insoluble drugs, or drugs that chelate with polyvalent metal cations, remain unclear. 
The aim of this study was to evaluate if one-time thylakoidrich spinach extract ingestion affects the gastrointestinal absorption of water-insoluble drugs and drugs that chelate with polyvalent metal cations. The plasma concentration-time profiles of griseofulvin (GF) and indomethacin (IM), two water-insoluble drugs, were studied in rats pretreated with thylakoid-rich spinach extract to assess the effect of thylakoidrich spinach extract on the absorption of orally administered water-insoluble drugs. Additionally, levels of various metals contained in the thylakoid-rich spinach extract preparation were measured, and the physicochemical interaction between drugs that chelate with polyvalent metal cations and thylakoidrich spinach extract was confirmed in vitro. Finally, the effect of co-administration of thylakoid-rich spinach extract and ciprofloxacin (CPFX), a quinolone antibiotic, on CPFX absorption was assessed in rats.

\section{MATERIALS AND METHODS}

Chemicals Thylakoid-rich spinach extract (Appethy ${ }^{\mathbb{R}}$; Lot No. PRS503071515) manufactured by Prospinach Inc. (Kimberly, ID, U.S.A.) was purchased from markets. The nutrition facts indicates that a serving size $(5 \mathrm{~g})$ of thylakoid-rich spinach extract contains $0.6 \mathrm{~g}$ fat, $2 \mathrm{~g}$ carbohydrate (of which $1.5 \mathrm{~g}$ was dietary fiber), $1 \mathrm{~g}$ protein, $10 \mathrm{mg}$ sodium, $150 \mathrm{mg}$ $\mathrm{Ca}$ and $6 \mathrm{mg} \mathrm{Fe}$. CPFX hydrochloride monohydrate, GF and levofloxacin (LVFX) were purchased from Tokyo Chemical Industry Co. (Tokyo, Japan). IM, cephalexin (CEX) and cefazolin (CEZ) sodium salt were purchased from Wako Pure Chemical Industries, Ltd. (Osaka, Japan). Tetracycline (TC) hydrochloride, $p$-acetamidophenol (APAP), theophylline (TP) and disodium ethylenediaminetetraacetate (EDTA) were obtained from Nacalai Tesque (Kyoto, Japan). All other reagents were of analytical or highest grade commercially available.

Analysis of Metals in Thylakoid-Rich Spinach Extract For metal analysis, $0.2 \mathrm{~g}$ thylakoid-rich spinach extract was treated with $4 \mathrm{~mL}$ nitric acid $(1+1)$ in a microwave oven (U1traWAVE; Milestone General, Kanagawa, Japan). The analysis was performed with Inductively Coupled Plasma-Atomic Emission Spectrometry (ICPS-8100; Shimadzu, Kyoto, Japan) for aluminum (Al), Ca, Fe, magnesium $(\mathrm{Mg})$ and Inductively Coupled Plasma-Mass Spectrometry (7700; Agilent Technologies, Tokyo, Japan) for copper $(\mathrm{Cu})$ and zinc $(\mathrm{Zn})$.

In Vitro Adsorption Studies CPFX, LVFX, TC, APAP, TP, CEX and CEZ were dissolved in ultrapure water at 1, 2.5, $1.25,1.5,1,1.25$ and $1 \mathrm{mg} / \mathrm{mL}$, respectively. Thylakoid-rich spinach extract $(25 \mathrm{mg})$ was added to $1 \mathrm{~mL}$ of each drug solution and mixed. In addition, thylakoid-rich spinach extract $(25 \mathrm{mg})$ and EDTA $(93 \mathrm{mg})$ as the chelating agent for metal cations were added to $1 \mathrm{~mL}$ of CPFX solution and mixed. The mixture was centrifuged at $21000 \times \boldsymbol{g}$ for $5 \mathrm{~min}$ at $25^{\circ} \mathrm{C}$. As control, thylakoid-rich spinach extract was not added to each drug solution and treated as described above. The supernatant fluid was diluted with ultrapure water (200-fold) and the drug concentrations were measured by Shimadzu HPLC system (Kyoto, Japan) equipped with an LC-10AD pump, according to the previous reports with some modifications. ${ }^{27,28)}$ Fluorescence detector $\left(\mathrm{RF}-10 \mathrm{~A}_{\mathrm{XL}}\right)$ was used to measure the concentration of CPFX, LVFX and TC, while UV detector (SPD$10 \mathrm{AV}$ ) was used to measure the concentration of APAP, TP, CEX and CEZ. Chromatographic conditions were as follows: mobile phase, $50 \mathrm{mM}$ citric acid-1 M ammonium acetate-acetonitrile $(87: 1: 12,(\mathrm{v} / \mathrm{v}))$ for CPFX and LVFX, $50 \mathrm{mM}$ sodium acetate buffer ( $\mathrm{pH}$ 6.5) containing $35 \mathrm{mM}$ calcium chloride and $25 \mathrm{mM}$ EDTA-methanol $(70: 30$, (v/v)) for TC, $30 \mathrm{mM}$ $\mathrm{KH}_{2} \mathrm{PO}_{4}$ buffer $(\mathrm{pH} 4.0)$ : methanol $(90: 10$, (v/v)) for APAP and $\mathrm{TP}, 30 \mathrm{mM} \mathrm{KH} \mathrm{PO}_{4}$ buffer ( $\mathrm{pH}$ 5.0)-methanol $(80: 20$, (v/v)) for CEX and CEZ; wave length, $335 \mathrm{~nm}$ (excitation) and $450 \mathrm{~nm}$ (emission) for CPFX and LVFX, $390 \mathrm{~nm}$ (excitation) and $512 \mathrm{~nm}$ (emission) for TC, $254 \mathrm{~nm}$ for APAP, $274 \mathrm{~nm}$ for $\mathrm{TP}, \mathrm{CEX}$ and CEZ; column temperature, $40^{\circ} \mathrm{C}$ for $\mathrm{CPFX}$, LVFX, APAP and TP, $50^{\circ} \mathrm{C}$ for TC, CEX and CEZ; flow rate, $1.5 \mathrm{~mL} / \mathrm{min}$ for all drugs. A Cosmosil 5C18-MS-II column ( $4.6 \times 150 \mathrm{~mm}, 5 \mu \mathrm{m}$; Nacalai Tesque) was used for all drugs.

The concentration of each drug and thylakoid-rich spinach extract were determined based on the standard clinical dose for oral administration or the serving size $(5 \mathrm{~g})$, and the volume of water intake $(200 \mathrm{~mL})$. However, the concentration of CEZ, used as an injection solution, was set to be same as the CPFX. The amount of EDTA used in this study was sufficiently dissolved in $1 \mathrm{~mL}$ of water; the concentration of EDTA would become excessive relative to the concentration of metal cations in thylakoid-rich spinach extract.

Animals Male Wistar rats (age, 10-11 weeks; weight, 230-270g) were purchased from SLC Japan (Hamamatsu, Japan). Rats were housed under standard conditions $\left(23 \pm 1{ }^{\circ} \mathrm{C}\right.$, $50 \pm 5 \%$ relative humidity) and maintained under a $12 \mathrm{~h}$ light/ dark cycle (light period: 8:00 a.m. to 8:00 p.m.) with free access to diet food and water for at least $5 \mathrm{~d}$ before use. All animal experiments were carried out according to the guidelines of the Faculty of Pharmacy, Meijo University for the Care and Use of Laboratory Animals.

In Vivo Pharmacokinetic Studies One day before examination, rats under anesthesia by intraperitoneal injection of sodium pentobarbital $(40 \mathrm{mg} / \mathrm{kg})$ were cannulated with polyethylene tubes into the right jugular vein for blood sampling. The rats were fasted for $16 \mathrm{~h}$ before the experiments but allowed free access to water. To avoid the food effect on drugs absorption, the fasting period was maintained until the end of blood collections.

For oral administration, thylakoid-rich spinach extract, GF and IM were suspended in $0.5 \%$ carboxymethylcellulose (CMC), and CPFX was dissolved in ultrapure water.

Effect of Thylakoid-Rich Spinach Extract on the Pharmacokinetics of GF and IM Rats received an oral administration of thylakoid-rich spinach extract $(100$ or $300 \mathrm{mg} / \mathrm{kg}$ $(2 \mathrm{~mL} / \mathrm{kg}))$ or $0.5 \% \mathrm{CMC}(2 \mathrm{~mL} / \mathrm{kg})$ as vehicle. Fifteen minutes after administration of thylakoid-rich spinach extract or vehicle, GF $(50 \mathrm{mg} / \mathrm{kg}(2 \mathrm{~mL} / \mathrm{kg}))$ or IM $(10 \mathrm{mg} / \mathrm{kg}(2 \mathrm{~mL} / \mathrm{kg}))$ was administered orally. Blood samples $(0.2 \mathrm{~mL})$ were collected through the cannula at $0.167,0.333,0.5,0.75,1,1.5,2,3,4,5$, $6,7,8,9$ and $10 \mathrm{~h}$ after the oral administration of drug. The samples were centrifuged at $11000 \times \boldsymbol{g}$ for $5 \mathrm{~min}$ at $4^{\circ} \mathrm{C}$, and the plasma fraction was stored at $-30^{\circ} \mathrm{C}$ until analysis.

Effect of Thylakoid-Rich Spinach Extract on the Pharmacokinetics of CPFX Rats received an oral administration of thylakoid-rich spinach extract $(500 \mathrm{mg} / \mathrm{kg}(3 \mathrm{~mL} / \mathrm{kg}))$ or $0.5 \% \mathrm{CMC}(3 \mathrm{~mL} / \mathrm{kg})$ as vehicle, and then CPFX $(20 \mathrm{mg} / \mathrm{kg}$ $(2 \mathrm{~mL} / \mathrm{kg}))$ was immediately administered orally. Blood samples $(0.2 \mathrm{~mL})$ were collected through the cannula at 0.167 , $0.333,0.5,0.75,1,1.5,2,3,4,5$ and $6 \mathrm{~h}$ after oral administration of CPFX. The samples were centrifuged at $11000 \times \boldsymbol{g}$ for 
5 min at $4^{\circ} \mathrm{C}$, and plasma fraction was stored at $-30^{\circ} \mathrm{C}$ until analysis.

Determination of Plasma Concentrations of GF, IM and CPFX The concentrations of GF, IM and CPFX in plasma were determined according to the reported procedure with some modifications, ${ }^{27,28)}$ using Shimadzu HPLC system and separation column Cosmosil 5C18-MS-II as described in "in vitro adsorption studies." For measurement of GF, $250 \mu \mathrm{L}$ of methanol containing lorazepam $(2 \mu \mathrm{g} / \mathrm{mL})$ as an internal standard was added to a $50 \mu \mathrm{L}$ plasma sample and mixed. After centrifugation at $21000 \times \boldsymbol{g}$ for $10 \mathrm{~min}$ at $25^{\circ} \mathrm{C}$, the supernatant $(200 \mu \mathrm{L})$ was evaporated to dryness under a nitrogen gas stream at $50{ }^{\circ} \mathrm{C}$. The resulting residue was reconstituted with $200 \mu \mathrm{L}$ of the mobile phase, and then aliquots of $50 \mu \mathrm{L}$ were injected into the HPLC system. The UV detector was set at $290 \mathrm{~nm}$, and the column temperature was $40^{\circ} \mathrm{C}$. The mobile phase was $30 \mathrm{mM} \mathrm{KH}_{2} \mathrm{PO}_{4}$ buffer $(\mathrm{pH}$ 5.0) and methanol $(50: 50,(\mathrm{v} / \mathrm{v}))$ solution, and the flow rate was $1.5 \mathrm{~mL} / \mathrm{min}$. For measurement of IM, $50 \mu \mathrm{L}$ of plasma samples and $200 \mu \mathrm{L}$ of acetonitrile containing mefenamic acid $(5 \mu \mathrm{g} / \mathrm{mL})$ as an internal standard were mixed. After centrifugation at $21000 \times \boldsymbol{g}$ for $10 \mathrm{~min}$ at $25^{\circ} \mathrm{C}, 20 \mu \mathrm{L}$ of the supernatant was injected into the HPLC system. The UV detector was set at $274 \mathrm{~nm}$, and the column temperature was $45^{\circ} \mathrm{C}$. The mobile phase was $30 \mathrm{mM}$ $\mathrm{KH}_{2} \mathrm{PO}_{4}$ buffer ( $\left.\mathrm{pH} 4.0\right)$ and acetonitrile $(50: 50$, (v/v)) solution, and the flow rate was $1.5 \mathrm{~mL} / \mathrm{min}$. For measurement of CPFX, $100 \mu \mathrm{L}$ of methanol containing $0.5 \%$ formic acid was added to a $50 \mu \mathrm{L}$ plasma sample and mixed. Then, $100 \mu \mathrm{L}$ of the mobile phase containing lomefloxacin $(0.25 \mu \mathrm{g} / \mathrm{mL})$ as an internal standard was added to the mixture. After vortex mixing, the mixture was centrifuged at $21000 \times \boldsymbol{g}$ for $10 \mathrm{~min}$ at $4^{\circ} \mathrm{C}$. The supernatant $(25 \mu \mathrm{L})$ was injected into the HPLC system using chromatographic conditions described above. The linear ranges for GF, IM and CPFX in rat plasma were $20-1500 \mathrm{ng} / \mathrm{mL}, 0.5-50 \mu \mathrm{g} / \mathrm{mL}$ and $25-1000 \mathrm{ng} / \mathrm{mL}$, respectively, with correlation coefficients $(r)$ greater than 0.999 .

Pharmacokinetic Analysis The plasma concentrationtime data of the drugs in each rat were analyzed individually using a noncompartmental model. The peak plasma concentration $\left(C_{\max }\right)$ and the time to reach $C_{\max }\left(T_{\max }\right)$ were obtained directly from the experimental data. The apparent elimination rate constant $\left(k_{\mathrm{el}}\right)$ calculated by log-linear regression of the terminal segment of the concentration-time profile. The area under the plasma concentration-time curve $(A U C)$ up to the last measured concentration $\left(C_{\mathrm{t}}\right)$ was calculated by the classical trapezoidal rule method $\left(A U C_{0-t}\right)$, and the $A U C$ from time zero to infinite $\left(A U C_{0-\infty}\right)$ was determined from $A U C_{0-\mathrm{t}}+\left(C_{\mathrm{t}} / k_{\mathrm{el}}\right)$. However, in the experiments of oral administration of $\mathrm{GF}$ as suspension, $k_{\mathrm{el}}$ could not calculate because enough plasma concentration data to calculate the $k_{\text {el }}$ could not be obtained in some rats during the experimental period $(0-10$ h)

Statistical Analysis All data are expressed as the mean \pm standard error (S.E.). Comparisons between two groups and three groups were performed by unpaired Student's $t$-test or one-way ANOVA fallowed by Dunnett's multiple comparison test, respectively. A value of $p<0.05$ was considered to be statistically significant.

\section{RESULTS}

Effect of Thylakoid-Rich Spinach Extract on the Pharmacokinetics of GF and IM Figure 1 shows the mean plasma concentration-time profiles of GF following oral administration to rats pretreated with vehicle or thylakoid-rich spinach extract. Notably, the mean plasma concentration-time profiles were similar between the vehicle and thylakoid-rich spinach extract $(100$ or $300 \mathrm{mg} / \mathrm{kg})$ pretreated rats. As summarized in Table 1 , there were no statistically significant differences in the $C_{\max }, T_{\max }$ and $A U C_{0-10 \mathrm{~h}}$ of GF between rats pretreated with vehicle or thylakoid-rich spinach extract. Likewise, pretreatment with thylakoid-rich spinach extract, did not alter the pharmacokinetic properties of orally administered IM (Fig. 2, Table 2).

Amount of Metals in Thylakoid-Rich Spinach Extract The amounts of metals in thylakoid-rich spinach extract are summarized in Table 3. Within the thylakoid-rich spinach extract samples, Ca $(26000 \mu \mathrm{g} / \mathrm{g})$ was the most abundant metal identified, while trace amounts of Al $(680 \mu \mathrm{g} / \mathrm{g}), \mathrm{Fe}(480 \mu \mathrm{g} / \mathrm{g})$, $\mathrm{Mg}(3800 \mu \mathrm{g} / \mathrm{g}), \mathrm{Cu}(6 \mu \mathrm{g} / \mathrm{g})$ and $\mathrm{Zn}(20 \mu \mathrm{g} / \mathrm{g})$ were also identified.

Interaction between CPFX and Thylakoid-Rich Spinach Extract with or without EDTA in Vitro Figure 3 shows the interaction of CPFX with thylakoid-rich spinach extract in vitro. In the presence of thylakoid-rich spinach extract, the CPFX concentration in the supernatant was significantly lower than the control. However, when CPFX and thylakoid-rich spinach extract were mixed with EDTA, the concentration of CPFX in the supernatant was unchanged.

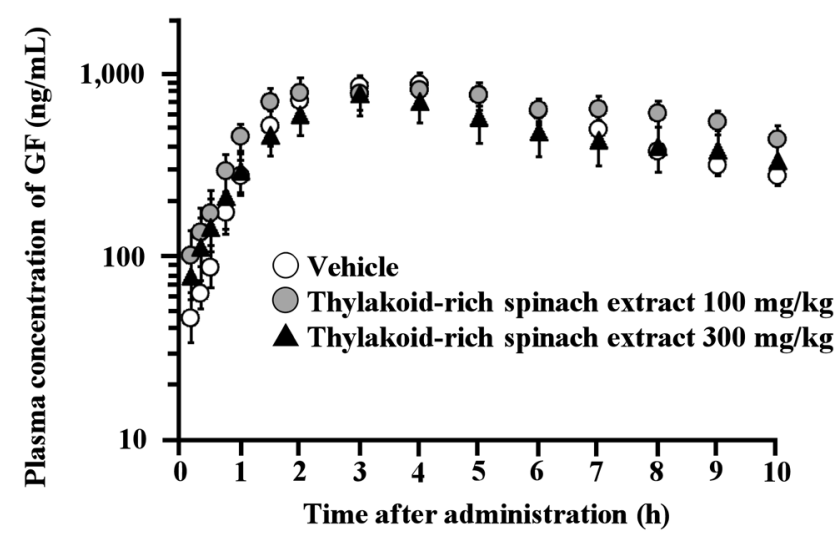

Fig. 1. Mean Plasma Concentration-Time Profiles of GF after Oral Administration in Rats Pretreated with Vehicle or Thylakoid-Rich Spinach Extract

Each symbol represents mean \pm S.E. $(n=5)$.

Table 1. Pharmacokinetics Parameters of GF after Oral Administration in Rats Pretreated with Vehicle or Thylakoid-Rich Spinach Extract

\begin{tabular}{lccc}
\hline \hline & $\begin{array}{c}C_{\max } \\
(\mathrm{ng} / \mathrm{mL})\end{array}$ & $\begin{array}{c}T_{\max } \\
(\mathrm{h})\end{array}$ & $\begin{array}{c}A U C_{0-10 \mathrm{~h}} \\
(\mathrm{ng} \cdot \mathrm{h} / \mathrm{mL})\end{array}$ \\
\hline Vehicle & $962.6 \pm 113.3$ & $4.0 \pm 0.5$ & $5494.6 \pm 1469.4$ \\
$\begin{array}{c}\text { Thylakoid-rich spinach } \\
\text { extract 100 mg/kg }\end{array}$ & $948.8 \pm 126.0$ & $4.0 \pm 0.9$ & $6348.2 \pm 1967.4$ \\
$\begin{array}{c}\text { Thylakoid-rich spinach } \\
\text { extract 300 mg/kg }\end{array}$ & $813.7 \pm 194.8$ & $3.4 \pm 0.2$ & $4907.0 \pm 1213.3$ \\
\hline
\end{tabular}

Data represents mean \pm S.E. $(n=5)$. 
Interaction between Six Drugs and Thylakoid-Rich Spinach Extract in Vitro The interaction between thylakoid-rich spinach extract and six drugs (LVFX, TC, APAP, TP, CEX, CEZ) was then assessed to ascertain whether thylakoid-rich spinach extract reduced the supernatant concentration of drugs across a variety of drug classes and

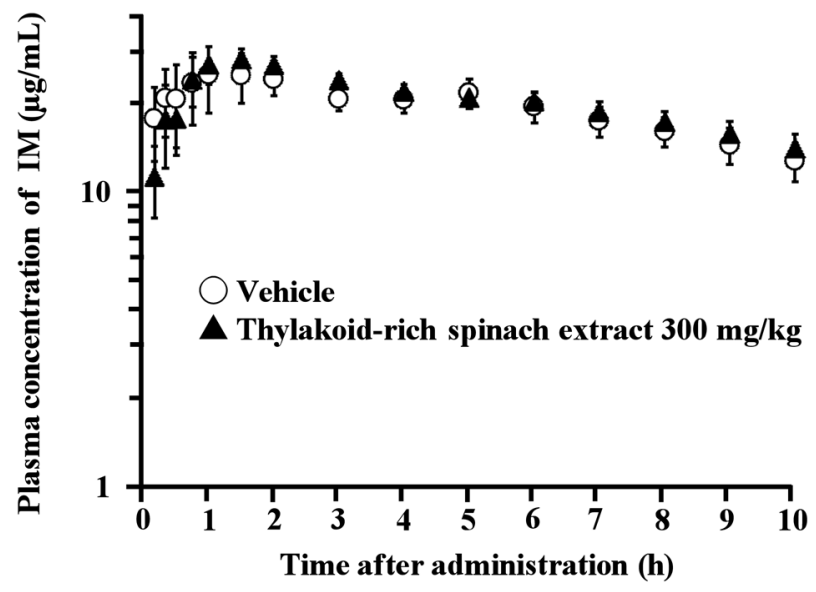

Fig. 2. Mean Plasma Concentration-Time Profiles of IM after Oral Administration in Rats Pretreated with Vehicle or Thylakoid-Rich Spinach Extract

Each symbol represents mean \pm S.E. $(n=5)$.

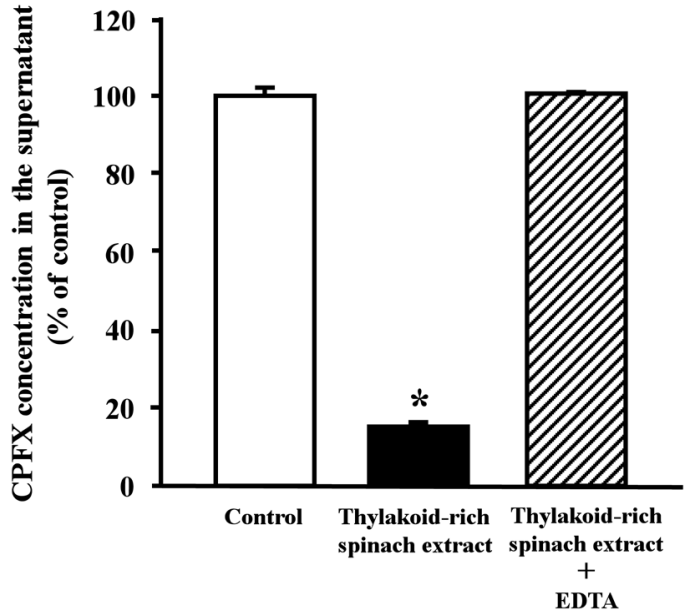

Fig. 3. Interaction between CPFX and Thylakoid-Rich Spinach Extract with or without EDTA in Vitro

Each column represents the mean \pm S.E. $(n=3)$. * Significantly different from the control $(p<0.05)$ structures that do and do not form a chelate with polyvalent metal cations (Fig. 4). Of note, the supernatant concentrations of LVFX and TC, which, like CPFX, chelate with polyvalent metal cations, were reduced relative to the control by up to 37 and $80 \%$, respectively. In contrast, the concentrations of APAP, TP, CEX and CEZ, which do not form a chelate with polyvalent metal cations, were nearly unchanged after mixing with thylakoid-rich spinach extract, although some of the data showed statistical significance.

Effect of Thylakoid-Rich Spinach Extract on the Phar-

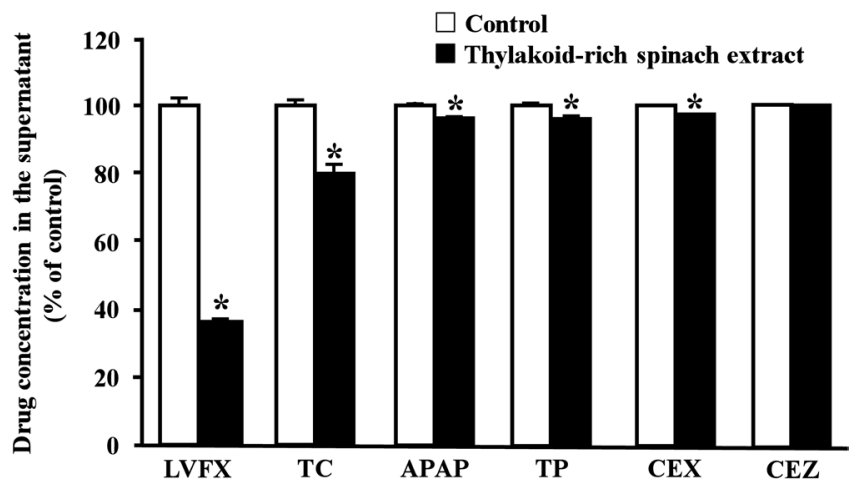

Fig. 4. Interaction between Six Drugs and Thylakoid-Rich Spinach Extract in Vitro

Each column represents the mean \pm S.E. $(n=3) . *$ Significantly different from the control $(p<0.05)$.

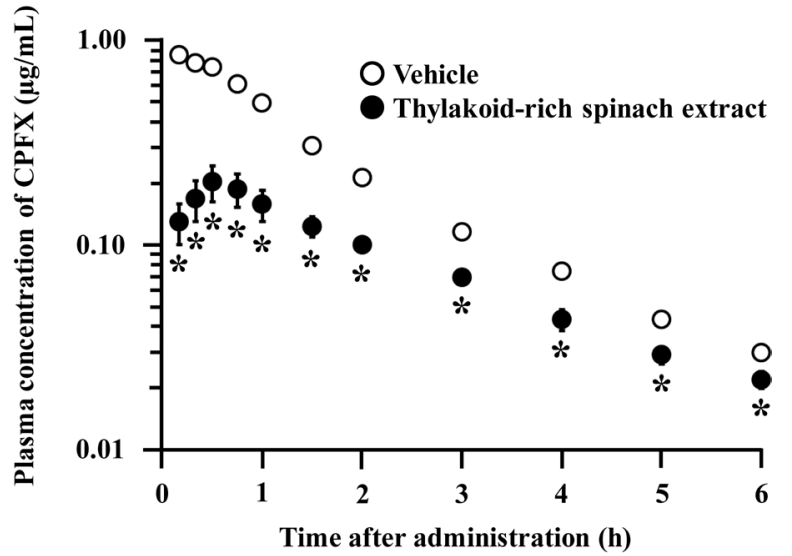

Fig. 5. Mean Plasma Concentration-Time Profiles of CPFX after Oral Administration in Rats Treated with Vehicle or Thylakoid-rich Spinach Extract

Each symbol represents mean \pm S.E. $(n=5-6)$. * Significantly different from the vehicle $(p<0.05)$.

Table 2. Pharmacokinetics Parameters of IM after Oral Administration in Rats Pretreated with Vehicle or Thylakoid-Rich Spinach Extract

\begin{tabular}{lcccc}
\hline \hline & $C_{\max }(\mu \mathrm{g} / \mathrm{mL})$ & $T_{\max }(\mathrm{h})$ & $A U C_{0-10 \mathrm{~h}}(\mu \mathrm{g} \cdot \mathrm{h} / \mathrm{mL})$ & $k_{\mathrm{el}}\left(\mathrm{h}^{-1}\right)$ \\
\hline Vehicle & $30.6 \pm 6.1$ & $2.3 \pm 0.9$ & $200.7 \pm 29.0$ & $0.12 \pm 0.03$ \\
Thylakoid-rich spinach extract $300 \mathrm{mg} / \mathrm{kg}$ & $33.1 \pm 3.2$ & $1.4 \pm 0.5$ & $214.0 \pm 14.4$ & $0.11 \pm 0.01$ \\
\hline
\end{tabular}

Data represents mean \pm S.E. $(n=5)$.

Table 3. Amount of Metals in Thylakoid-Rich Spinach Extract

\begin{tabular}{ccccc}
\hline \hline $\mathrm{Ca}(\mu \mathrm{g} / \mathrm{g})$ & $\mathrm{Al}(\mu \mathrm{g} / \mathrm{g})$ & $\mathrm{Fe}(\mu \mathrm{g} / \mathrm{g})$ & $\mathrm{Mg}(\mu \mathrm{g} / \mathrm{g})$ & $\mathrm{Cu}(\mu \mathrm{g} / \mathrm{g})$ \\
\hline 26000 & 680 & 480 & 3800 & $\mathrm{Zn}(\mu \mathrm{g} / \mathrm{g})$ \\
\hline
\end{tabular}

Each value represents $\mu \mathrm{g}$ per $1 \mathrm{~g}$ thylakoid-rich spinach extract. 
Table 4. Pharmacokinetics Parameters of CPFX after Oral Administration in Rats Treated with Vehicle or Thylakoid-Rich Spinach Extract

\begin{tabular}{llll}
\hline \hline & $C_{\max }(\mu \mathrm{g} / \mathrm{mL})$ & $T_{\max }(\mathrm{h})$ & $A U C_{0-\infty}(\mu \mathrm{g} \cdot \mathrm{h} / \mathrm{mL})$ \\
\hline Vehicle & $0.85 \pm 0.04$ & $0.28 \pm 0.07$ & $1.36 \pm 0.05$ \\
Thylakoid-rich spinach extract & $0.21 \pm 0.03 *$ & $1.05 \pm 0.49$ & $0.46 \pm 0.02$ \\
\hline
\end{tabular}

Data represents mean \pm S.E. $(n=5-6) . *$ Significantly different from the vehicle $(p<0.05)$.

macokinetics of CPFX Figure 5 shows the mean plasma concentration-time profiles for CPFX alone and with coadministration of thylakoid-rich spinach extract in rats. Coadministration of thylakoid-rich spinach extract significantly reduced the plasma concentration of CPFX at all sampling points. The corresponding pharmacokinetic parameters are summarized in Table 4. Of particular interest, co-administration of thylakoid-rich spinach extract significantly reduced the $C_{\max }$ and $A U C_{0-\infty}$ of CPFX relative to CPFX alone by 25 and $40 \%$, respectively. However, there were no significant differences in the $k_{\mathrm{el}}$, and the $T_{\max }$ appeared to be prolonged by thylakoid-rich spinach extract, although this was not statistically significant.

\section{DISCUSSION}

In this study, the effect of one-time thylakoid-rich spinach extract ingestion on the gastrointestinal absorption of waterinsoluble drugs and drugs that chelate with polyvalent metal cations was evaluated. For the in vivo rat experiments, GF was administered at $50 \mathrm{mg} / \mathrm{kg}$ and IM at $10 \mathrm{mg} / \mathrm{kg}$, which was based on previous study. ${ }^{28)}$ The pharmacokinetic parameters (such as $C_{\max }, T_{\max }$, and $k_{\mathrm{el}}$ ) of GF and IM observed in the vehicle, were consistent with those reported by previous studies. ${ }^{29,30)}$ While thylakoid-rich spinach extract was given at $100 \mathrm{mg} / \mathrm{kg}$, which was based on the human serving size $(5 \mathrm{~g})$, assuming human body weight as $50 \mathrm{~kg}$. When rats were given the serving or a 3-fold higher size of thylakoid-rich spinach extract, there was little change in the pharmacokinetics of GF and IM (Figs. 1, 2, and Tables 1, 2). These results suggest that one-time thylakoid-rich spinach extract ingestion at the serving size does not affect the gastrointestinal absorption of water-insoluble drugs.

Interestingly, Matsuda et al. have reported that oral administration of thylakoid-rich spinach extract at $200 \mathrm{mg} / \mathrm{kg}$ with corn oil, but not $100 \mathrm{mg} / \mathrm{kg}$, significantly increases fecal total lipid and bile acid volumes in rats. Further, the bile acid binding capacity of thylakoid-rich spinach extract was increased in $0.1 \mathrm{M}$ phosphate buffer ( $\mathrm{pH}$ 6.8) in vitro in a concentrationdependent manner. ${ }^{15)}$ However, there were no significant differences in the pharmacokinetic parameters of GF and IM in this study, although rats were administered $300 \mathrm{mg} / \mathrm{kg}$ thylakoid-rich spinach extract (Figs. 1, 2, and Tables 1, 2). A possible reason for this is pepsin, trypsin and pancreatic juice digest thylakoid-rich spinach extract. ${ }^{31)}$ Therefore, the thylakoid-rich spinach extract probably could not bind the bile acid at full capacity as the thylakoid-rich spinach extract was digested by these enzymes, although we could not clear up the exact details.

To determine the effect of thylakoid-rich spinach extract on the pharmacokinetics of drugs that chelate with polyvalent metal cations, the content of metals in thylakoid-rich spinach extract was measured. The results demonstrate that a serving size of thylakoid-rich spinach extract contains a large amount of $\mathrm{Ca}(130 \mathrm{mg} / 5 \mathrm{~g})$, and low amounts of $\mathrm{Al}(3.4 \mathrm{mg} / 5 \mathrm{~g})$, $\mathrm{Fe}(2.4 \mathrm{mg} / 5 \mathrm{~g}), \mathrm{Mg}(19 \mathrm{mg} / 5 \mathrm{~g}), \mathrm{Cu}(0.03 \mathrm{mg} / 5 \mathrm{~g})$ and $\mathrm{Zn}$ $(0.1 \mathrm{mg} / 5 \mathrm{~g})$ (Table 3). Generally, it is well-known that spinach is rich in minerals, such as $\mathrm{Ca}, \mathrm{Mg}, \mathrm{Fe}$ and $\mathrm{Al}^{32)}$ For preparation of thylakoid-rich spinach extract, Appethyl ${ }^{\circledR}$, reagents containing these metals are not used. ${ }^{12}$ ) Thus, we speculate that these metals in the thylakoid-rich spinach extract are derived from spinach itself. However, it is possible that content of metals in other thylakoid-rich spinach extract preparations may differ. It will be necessary to ascertain the content of metals in other preparations.

Stojković et al. have reported that CPFX hydrochloride concentrations are significantly reduced when dissolved in media containing metallic compounds, such as $\mathrm{Al}(\mathrm{OH})_{3}, \mathrm{CaCO}_{3}$, $\mathrm{FeSO}_{4}$, and $\mathrm{ZnSO}_{4}$, relative to $\mathrm{CPFX}$ hydrochloride dissolved in water. ${ }^{24)}$ This aligns with our data, which showed a significant decrease in the supernatant concentration of CPFX following centrifugation of a mixture of thylakoid-rich spinach extract and CPFX. Further, when EDTA was included in the mixture, the concentration of CPFX was unchanged (Fig. 3); indicating that the physicochemical interaction between CPFX and metal cations found in thylakoid-rich spinach extract occurs in vitro.

Furthermore, we examined the effect of co-administration of thylakoid-rich spinach extract on the pharmacokinetics of CPFX in vivo, using rats. In this study, CPFX and thylakoidrich spinach extract were administered to rats based on the standard clinical dose and serving size, respectively. Briefly, the human body weight was assumed to be $50 \mathrm{~kg}$, the standard clinical dose of CPFX is $4 \mathrm{mg} / \mathrm{kg}(200 \mathrm{mg} / 50 \mathrm{~kg})$, and the dose of thylakoid-rich spinach extract is $100 \mathrm{mg} / \mathrm{kg}(5 \mathrm{~g} / 50 \mathrm{~kg})$; making the dose ratio $1: 25$. However, the bioavailability of CPFX after oral administration is reported to be $20 \%$ in rats, ${ }^{33)}$ while, bioavailability in humans is $69 \%{ }^{34)}$ In addition, the elimination half-life in the rat is $1.55 \mathrm{~h},{ }^{33)}$ compared to $4.11 \mathrm{~h}$ in humans. ${ }^{34)}$ Therefore, considering these differences between rats and humans, the dose of CPFX was set at $20 \mathrm{mg} / \mathrm{kg}$ for rats, which is 5-fold higher than that of humans, to ensure the $C_{\max }$ would be approximately the same. Accordingly, thylakoid-rich spinach extract was administered at $500 \mathrm{mg} / \mathrm{kg}$ to keep the dose ratio of $1: 25$. Co-administration of thylakoid-rich spinach extract and CPFX resulted in a marked reduction in the $C_{\max }$ and $A U C_{0_{-\infty}}$ of CPFX, but did not affect the $k_{\mathrm{el}}$ (Fig. 5 and Table 4). The pharmacokinetic parameters of CPFX in the vehicle, such as $C_{\max }, T_{\max }, A U C_{0-\infty}$, and $k_{\mathrm{el}}$, were consistent with those reported by previous studies. $^{33,35)}$ Based on these findings; namely that Ca was the most abundant metal in the thylakoid-rich spinach extract and that addition of EDTA interfered with the interaction between CPFX and thylakoid-rich spinach extract in vitro, we infer that 
the reduced bioavailability of CPFX was a result of chelate formation with polyvalent metal cations, notably $\mathrm{Ca}^{2+}$. Additionally, thylakoid-rich spinach extract markedly reduced LVFX and TC concentrations in the supernatant in vitro, while the reduction of APAP, TP, and CEX concentrations was negligible (Fig. 4). This implies that the intake of thylakoidrich spinach extract may reduce the absorption of a variety of drugs that chelate with polyvalent metal cations. Incidentally, the slight reduction of APAP, TP, and CEX concentrations by thylakoid-rich spinach extract in vitro, may have been mediated by the dietary fiber in thylakoid-rich spinach extract as both APAP and TP have been shown to adsorb to dietary fiber, such as cellulose, chitosan, pectin, sodium alginate and glucomannan. ${ }^{36)}$

It is important to note, however, that the possible effect of thylakoid-rich spinach extract on intestinal organic aniontransporting polypeptide (OATP) cannot be excluded. It has been reported that intestinal absorption of CPFX involves passive diffusion and transporters, such as P-gp, organic anion transporters and OATP, ${ }^{37)}$ and also that the $C_{\max }$ and $A U C$ of CPFX are significantly reduced when given orally with orange juice containing OATP inhibitor. ${ }^{38)}$ Further study is needed to elucidate the effect of thylakoid-rich spinach extract on OATP.

Our results also demonstrate that thylakoid-rich spinach extract administration prolonged the $T_{\max }$ of CPFX (Fig. 5 and Table 4), although chelate formation with polyvalent metal cations did not affect the $T_{\max }$ of CPFX. ${ }^{17,19-21)}$ Of note, a similar result was observed when rats received an oral administration of CPFX with food. ${ }^{39)}$ Moreover, Stenblom et al. have reported that a delay in gastric emptying mediated by food intake. ${ }^{40)}$ Therefore, this phenomenon may be ascribed to the fact that gastric emptying was delayed by thylakoid-rich spinach extract. ${ }^{41)}$ Conversely, we observed that the $T_{\max }$ of GF and IM was not affected by thylakoid-rich spinach extract; this is likely because dissolution is a rate-limiting step for gastrointestinal absorption of GF and IM, which are poorly water-soluble.

In conclusion, the results of the present study indicate that co-administration of CPFX and thylakoid-rich spinach extract reduce the plasma concentration of CPFX in rats through an interaction between $\mathrm{CPFX}$ and the polyvalent metal cations in thylakoid-rich spinach extract. However, one-time thylakoidrich spinach extract ingestion at the serving size did not affect the gastrointestinal absorption process of water-insoluble drugs in rats. Therefore, intake of thylakoid-rich spinach extract may reduce the absorption of drugs that form a chelate with polyvalent metal cations. It will be necessary to clarify the effect of co-administration of other thylakoid-rich spinach extract preparations with drugs that chelate with polyvalent metal cations. Further clinical research should be conducted to confirm these results in humans.

Conflict of Interest The authors declare no conflict of interest.

\section{REFERENCES}

1) Chiba T, Sato $Y$, Nakanishi T, Yokotani K, Suzuki S, Umegaki $\mathrm{K}$. Inappropriate usage of dietary supplements in patients by miscommunication with physicians in japan. Nutrients, 6, 5392-5404 (2014).
2) Wu CH, Wang CC, Kennedy J. Changes in herb and dietary supplement use in the U.S. adult population: A comparison of the 2002 and 2007 national health interview surveys. Clin. Ther., 33, 17491758 (2011).

3) Alsanad SM, Williamson EM, Howard RL. Cancer patients at risk of herb/food supplement-drug interactions: a systematic review. Phytother. Res., 28, 1749-1755 (2014).

4) Végh A, Lankó E, Fittler A, Vida RG, Miseta I, Takács G, Botz L. Identification and evaluation of drug-supplement interactions in hungarian hospital patients. Int. J. Clin. Pharmacol., 36, 451-459 (2014).

5) Mai I, Bauer S, Perloff ES, Johne A, Uehleke B, Frank B, Budde $\mathrm{K}$, Roots I. Hyperforin content determines the magnitude of the St John's wort-cyclosporine drug interaction. Clin. Pharmacol. Ther., 76, 330-340 (2004).

6) Johne A, Brockmöller J, Bauer S, Maurer A, Langheinrich M, Roots I. Pharmacokinetic interaction of digoxin with an herbal extract from St John's wort (Hypericum perforatum). Clin. Pharmacol. Ther., 66, 338-345 (1999).

7) Piscitelli SC, Burstein AH, Chaitt D, Alfaro RM, Falloon J. Indinavir concentrations and St John's wort. Lancet, 355, 547-548 (2000).

8) Galluzzi S, Zanetti O, Binetti G, Trabucchi M, Frisoni GB. Coma in a patient with Alzheimer's disease taking low dose trazodone and ginkgo biloba. J. Neurol. Neurosurg. Psychiatry, 68, 679-680 (2000).

9) Dave AA, Samuel J. Suspected interaction of cranberry juice extracts and tacrolimus serum levels: a case report. Cureus, 8, e610 (2016).

10) Nayeri A, Wu S, Adams E, Tanner C, Meshman J, Saini I, Reid W. Acute calcineurin inhibitor nephrotoxicity secondary to turmeric intake: a case report. Transplant. Proc., 49, 198-200 (2017).

11) Woodward CJ, Deyo ZM, Donahue KE, Deal AM, Hawes EM. Clinically relevant interaction between warfarin and scuppernongs, a quercetin containing muscadine grape: continued questions surrounding flavonoid-induced warfarin interactions. BMJ Case Rep., 2014 (jun25 1), 1-4 (2014).

12) Emek SC, Szilagyi A, Åkerlund HE, Albertsson PÅ, Köhnke R, Holm A, Erlanson-Albertsson C. A large scale method for preparation of plant thylakoids for use in body weight regulation. Prep. Biochem. Biotechnol., 40, 13-27 (2010).

13) Stenblom EL, Egecioglu E, Landin-Olsson M, Erlanson-Albertsson C. Consumption of thylakoid-rich spinach extract reduces hunger, increases satiety and reduces cravings for palatable food in overweight women. Appetite, 91, 209-219 (2015).

14) Montelius C, Erlandsson D, Vitija E, Stenblom EL, Egecioglu E, Erlanson-Albertsson C. Body weight loss, reduced urge for palatable food and increased release of GLP-1 through daily supplementation with green-plant membranes for three months in overweight women. Appetite, 81, 295-304 (2014).

15) Matsuda H, Ooi S, Otokozawa R, Kumazaki K, Udagawa E, Asakura $M$, Suzuki $D$, Shirai $T$. Intake of green-plant membrane with dietary oil suppresses postprandial hypertriglyceridemia in rats via promoting excretion of bile acids. Biosci. Biotechnol. Biochem., 82, 114-119 (2018).

16) Holm R, Müllertz A, Mu H. Bile salts and their importance for drug absorption. Int. J. Pharm., 453, 44-55 (2013).

17) Nix DE, Watson WA, Lener ME, Frost RW, Krol G, Goldstein H, Lettieri J, Schentag JJ. Effects of aluminum and magnesium antacids and ranitidine on the absorption of ciprofloxacin. Clin. Pharmacol. Ther., 46, 700-705 (1989).

18) Nix DE, Wilton JH, Ronald B, Distlerath L, Williams VC, Norman A. Inhibition of norfloxacin absorption by antacids. Antimicrob. Agents Chemother., 34, 432-435 (1990).

19) Kara M, Hasinoff BB, Mckay DW, Campbell NR. Clinical and chemical interactions between iron preparations and ciprofloxacin. Br. J. Clin. Pharmacol., 31, 257-261 (1991). 
20) Sahai J, Healy DP, Stotka J, Polk RE. The influence of chronic administration of calcium carbonate on the bioavailability of oral ciprofloxacin. Br. J. Clin. Pharmacol., 35, 302-304 (1993).

21) Neuvonen PJ, Kivistö KT, Lehto P. Interference of dairy products with the absorption of ciprofloxacin. Clin. Pharmacol. Ther., 50, 498-502 (1991)

22) Kivistö KT, Ojala-Karlsson P, Neuvonen PJ. Inhibition of norfloxacin absorption by dairy products. Antimicrob. Agents Chemother., 36, 489-491 (1992).

23) Parojčić J, Stojković A, Tajber L, Grbić S, Paluch KJ, Djurić Z, Corrigan OI. Biopharmaceutical characterization of ciprofloxacin HCl-ferrous sulfate interaction. J. Pharm. Sci., 100, 5174-5184 (2011).

24) Stojković A, Tajber L, Paluch KJ, Djurić Z, Parojčić J, Corrigan OI. Biopharmaceutical characterization of ciprofloxacin-metallic ion interactions: Comparative study into the effect of aluminium, calcium, zinc and iron on drug solubility and dissolution. Acta Pharm., 64, 77-88 (2014)

25) Simon Z, Katja B, Darko U, Marjan V, Albin K. Metal cationfluoroquinolone complexes do not permeate through the intestinal absorption barrier. J. Pharm. Biomed. Anal., 53, 655-659 (2010).

26) Garty M, Hurwitz A. Effect of cimetidine and antacids on gastrointestinal absorption of tetracycline. Clin. Pharmacol. Ther., 28, 203-207 (1980).

27) Ohnishi M, Hitoshi K, Katoh M, Nadai M, Abe F, Kurono S, Saito $\mathrm{H}$, Haniuda M, Hasegawa T. Effect of a kampo preparation, byakkokaninjinto, on pharmacokinetics of ciprofloxacin and tetracycline. Biol. Pharm. Bull., 32, 1080-1084 (2009).

28) Nadai M, Tajiri C, Yoshizumi H, Suzuki Y, Zhao YL, Kimura M, Tsunekawa Y, Hasegawa T. Effect of chitosan on gastrointestinal absorption of water-insoluble drugs following oral administration in rats. Biol. Pharm. Bull., 29, 1941-1946 (2006).

29) Bloedow DC, Hayton WL. Effects of lipids on bioavailability of sulfisoxazole acetyl, dicumarol, and griseofulvin in rats. J. Pharm. Sci., 65, 328-334 (1976).

30) Cattani VB, Pohlmann AR, Dalla Costa T. Pharmacokinetic evaluation of indomethacin ethyl ester-loaded nanoencapsules. Int. J. Pharm., 363, 214-216 (2008)

31) Emek SC, Åkerlund H-E, Clausén M, Ohlsson L, Weström B,
Erlanson-Albertsson C, Albertsson P-Å. Pigments protect the light harvesting proteins of chloroplast thylakoid membranes against digestion by gastrointestinal proteases. Food Hydrocoll., 25, 16181626 (2011).

32) Rahmatollah R, Mahbobeh R. Mineral contents of some plants used in Iran. Pharmacognosy Res., 2, 267-270 (2010).

33) Hwang YH, Cho WK, Jang D, Ha JH, Jung K, Yun HI, Ma JY. Effects of berberine and hwangryunhaedok-tang on oral bioavailability and pharmacokinetics of ciprofloxacin in rats. Evid. Based Complement. Alternat. Med., 2012, 1-7 (2012).

34) Plaisance KI, Drusano GL, Forrest A, Bustamante CI, Standiford HC. Effect of dose size on bioavailability of ciprofloxacin. Antimicrob. Agents Chemother., 31, 956-958 (1987).

35) Hwang YH, Yang HJ, Kim DG, Ma JY. Inhibitory effects of multiple-dose treatment with baicalein on the pharmacokinetics of ciprofloxacin in rats. Phytother. Res., 31, 69-74 (2017).

36) Watanabe $\mathrm{S}$, Inoue $\mathrm{N}$, Imai $\mathrm{K}$, Suemaru $\mathrm{K}$, Araki $\mathrm{H}$, Aimoto $\mathrm{T}$. Interaction of drugs with dietary fiber-adsorption of drugs onto dietary fiber in in vitro study-. Jpn. J. Pharm. Health Care Sci., 32, 221-226 (2006)

37) Arakawa H, Shirasaka Y, Haga M, Nakanishi T, Tamai I. Active intestinal absorption of fluoroquinolone antibacterial agent ciprofloxacin by organic anion transporting polypeptide, Oatpla5. Biopharm. Drug Dispos., 33, 332-341 (2012).

38) Neuhofel AL, Wilton JH, Victory JM, Hejmanowski LG, Amsden GW. Lack of bioequivalence of ciprofloxacin when administered with calcium-fortified orange juice: a new twist on an old interaction. J. Clin. Pharmacol., 42, 461-466 (2002).

39) Imaoka A, Abiru K, Akiyoshi T, Ohtani H. Food intake attenuates the drug interaction between new quinolones and aluminum. $J$. Pharm. Health Care Sci., 4, 11 (2018).

40) Choe SY, Neudeck BL, Welage LS, Amidon GE, Barnett JL, Amidon GL. Novel method to assess gastric emptying in humans: the pellet gastric emptying test. Eur. J. Pharm. Sci., 14, 347-353 (2001).

41) Stenblom EL, Weström B, Linninge C, Bonn P, Farrell M, Rehfeld JF, Montelius C. Dietary green-plant thylakoids decrease gastric emptying and gut transit, promote changes in the gut microbial flora, but does not cause steatorrhea. Nutr. Metab., 13, 67 (2016). 